\title{
Feeding behaviors of transition dairy cows fed glycerol as a replacement for corn
}

\author{
E. R. Carvalho, ${ }^{\star 1}$ N. S. Schmelz-Roberts, ${ }^{*}$ H. M. White, ${ }^{*}$ C. S. Wilcox, ${ }^{\star}$ S. D. Eicher, $\dagger$ and S. S. Donkin ${ }^{\star 2}$ \\ *Department of Animal Sciences, Purdue University, West Lafayette, IN 47907 \\ †US Department of Agriculture-Agricultural Research Service, Livestock Behavior Research Unit, West Lafayette, IN 47907
}

\begin{abstract}
Feed sorting is a natural behavior of dairy cows that can result in inconsistencies in the nutritive value of a total mixed ration (TMR). The objective of this study was to determine the effects of replacing high-moisture corn with glycerol on feed sorting and the feed intake pattern of transition dairy cows. Multiparous Holstein cows $(\mathrm{n}=26)$ were paired by expected calving date, housed in individual tie stalls, and fed diets containing either glycerol or high-moisture corn once daily from $\mathrm{d}$ -28 to +56 relative to calving. Glycerol was included at 11.5 and $10.8 \%$ of the ration dry matter for the pre- and postpartum diets, respectively. The feed consumption pattern was determined by measuring TMR disappearance during the intervals from 0 to $4 \mathrm{~h}, 4$ to $8 \mathrm{~h}, 8$ to $12 \mathrm{~h}$, and 12 to $24 \mathrm{~h}$ relative to feed delivery. Feed sorting was determined on $\mathrm{d}-16,-9,9,16$, and 51 relative to calving at $4,8,12$ and $24 \mathrm{~h}$ after feeding. The TMR particle size profile was determined at feed delivery and at 4, 8, 12, and 24 after feed delivery by using the Penn State Particle Separator (Nasco, Fort Atkinson, WI) to yield long $(>19 \mathrm{~mm})$, medium $(<19$ $\mathrm{mm},>8 \mathrm{~mm})$, short $(<8 \mathrm{~mm},>1.18 \mathrm{~mm})$, and fine $(<1.18 \mathrm{~mm})$ particles. Overall feed intake did not differ between diets and was $14.7 \pm 0.4$ and $20.2 \pm 0.5 \mathrm{~kg} / \mathrm{d}$ for the pre- and postpartum intervals, respectively. During the prepartum period, glycerol decreased the amount of feed consumed during the first $4 \mathrm{~h}$ after feed delivery (7.22 vs. $5.59 \pm 0.35 \mathrm{~kg}$; control vs. glycerol, respectively) but increased feed consumed from 12 through 24 $\mathrm{h}$ after feed delivery ( 2.22 vs. $3.82 \pm 0.35 \mathrm{~kg}$; control vs. glycerol, respectively). Similar effects on the feed consumption pattern were observed after calving. During the prepartum period, cows fed the control diet sorted against long particles, whereas cows fed glycerol did not sort against long particles (77.2 vs. $101.5 \pm 3.50 \%$
\end{abstract}

\footnotetext{
Received July 1, 2010.

Accepted August 22, 2012.

${ }^{1}$ Current address: Instituto Federal Goiano, Campus Iporá, Goiás, Brazil, 76200-000.

${ }^{2}$ Corresponding author: sdonkin@purdue.edu
}

of expected intake for control vs. glycerol; significant treatment effect). The data indicate that addition of glycerol to the TMR alters the feed consumption pattern to increase feed consumption late in the day at the expense of feed consumed immediately after feeding, and it reduces sorting behavior against long particles. Together, these may reduce diurnal variations in the rumen environment to promote greater rumen health in transition cows.

Key words: glycerol, feeding behavior, transition cow

\section{INTRODUCTION}

Cattle have the intrinsic ability to select specific and needed nutrients when feeds are offered separately (Stricklin and Kautz-Scanavy, 1983). Feeding rations as a TMR is a common practice in the US dairy industry; however; one concern about TMR feeding is the ability of cows to selectively consume, or sort, various feed components from their ration. Cows have been shown to prefer the grain component of the TMR and discriminate against the longer forage components (Leonardi and Armentano, 2003), which can lead to consumption of rations that fail to meet the cows' daily nutrient needs or result in suboptimal rumen fermentation patterns (DeVries et al., 2007, 2008). Transition dairy cows are at a greater risk of developing metabolic and infectious diseases than at any other time during their lives (Grummer, 1995; Drackley, 1999). Therefore, special attention must be paid to diet formulation and feeding management practices for transition cows to minimize feed sorting behaviors and avoid consumption of a ration with compromised nutritive value (Stone, 2004).

When dominant and subordinate cows are grouped together in free-stalls, feed sorting by dominant cows is also likely to affect the nutritional value of the diet such that the cows may consume a diet with a greater energy density and leave behind an energy-compromised diet for subordinate cows (Krause and Oetzel, 2006). Likewise, with a greater interval of time that elapses after feed delivery, the likelihood is greater that feed sorting has occurred, resulting in available feed that 
deviates from the target nutrient and particle profile for a particular TMR (DeVries et al., 2005).

Several additions to rations fed as a TMR have been investigated in an attempt to reduce feed sorting. Molasses has been recognized for its property to conglomerate small feed particles to larger particles. The addition of molasses to corn silage-based diets decreased feed sorting, suggesting that molasses might be beneficial to enhance the uniformity of TMR consumption for group-fed cows (Oelker et al., 2009; DeVries and Gill, 2012). Likewise, the addition of molasses reduced the percentage of fine particles found in calf starter (Lesmeister and Heinrichs, 2005). Glycerol is a by-product of the biodiesel industry and has recently been shown to be a suitable primary feed ingredient to replace corn grain in rations fed to midlactation dairy cows (Donkin et al., 2009). Glycerol is a sweet-tasting (Lee, 1987), viscous liquid that has been used in the food industry because of its ability to enhance the water-holding capacity (Farahnaky et al., 2009) and sweetness (Roper, 2007) of foods. Furthermore, glycerol has been shown to stimulate gustatory chemoreceptors in ruminants that sense the sweet taste (Bell and Kitchell, 1966), and early-lactation dairy cattle have been shown to prefer sweet-tasting feeds (Nombekela et al., 1994). Therefore, we hypothesized that glycerol in rations for transition cows would increase the selective consumption of long particles in the TMR, either as a consequence of coating of particles or through minimizing particle separation. Furthermore, we hypothesized that day relative to calving would affect feed sorting and consumption patterns. The objective of this experiment was to determine the effect of substituting glycerol for corn grain on the feed sorting and eating patterns of transition dairy cows.

\section{MATERIALS AND METHODS}

\section{Housing and Management}

Twenty-six Holstein multiparous cows were selected for the study, paired by expected calving date, and housed in individual tie stalls at the Purdue Dairy Research and Education Center (Purdue University, West Lafayette, IN). Cows were randomly assigned to diets containing either high-moisture corn (control) or glycerol and fed diets formulated to meet the NRC (2001) guidelines for $600-\mathrm{kg}$ dairy cattle from -28 through $+56 \mathrm{~d}$ relative to calving (DRTC). The experiment lasted from May 28, 2009, through October 25, 2009. Three cows were removed from the study, 2 for displaced abomasum (1 each for the control and glycerol groups) and 1 for uterine torsion (control group). Twenty-three cows completed the study, with 12 in the glycerol group and 11 in the control group. Protocols for animal care and use were approved by the Purdue University Animal Care and Use Committee.

\section{Diets and Treatments}

The ingredients and nutrient composition of the preand postpartum diets are presented in Table 1. Descriptions of the diets, the production response, and the metabolic profiles of cows have been detailed elsewhere (Carvalho et al., 2011), but some of the data are repeated here to assist in evaluating the feeding behavior. Diets were fed once daily between 0630 to $0730 \mathrm{~h}$ in amounts that ensured ad libitum intake, and 10 to $15 \%$ of the feed offered remaining in the bunk at the end of $24 \mathrm{~h}$ on an as-fed basis. The amount of feed refused was measured daily, and feed intake was determined by difference, assuming a similar DM content of feed offered and feed refused. This level of overfeeding was intended to provide adequate quantities of feed in the bunk at all times. The average orts and standard deviation, as a percentage of feed offered, was $13.6 \pm 9.6 \%$ based on 1,966 observations. Samples of TMR were collected weekly, dried in a forced-air oven for $72 \mathrm{~h}$ at $55^{\circ} \mathrm{C}$, and ground using a Wiley mill (Thomas Scientific, Swedesboro, NJ) to pass a 1-mm screen. Composite samples were formed monthly and analyzed by a commercial laboratory (Dairy One, Ithaca, NY) for DM, CP, ADF, starch, and minerals by wet chemistry following AOAC International (2000) procedures, and for NDF following the method of Goering and Van Soest (1970).

\section{Feed Intake and Sorting}

The feed consumption pattern and feed sorting were determined on $\mathrm{d}-16,-9,9,16$, and 51 relative to calving. Feed consumption and feed sorting behavior were determined at $4,8,12$, and $24 \mathrm{~h}$ relative to feed delivery. At each of the times indicated, the remaining feed for each cow was removed briefly, weighed, and mixed, and a 1.4-L subsample was obtained for particle size analysis, with the remaining feed returned to the cow. Feed was not pushed up to cows in between the sampling times. A subsample of the unsorted TMR and the total TMR delivery weight were obtained at feeding $(0 \mathrm{~h})$. Samples of diets were frozen at $-20^{\circ} \mathrm{C}$ pending analysis, and upon thawing, samples were size separated using the Penn State Particle Separator (PSPS, Nasco, Fort Atkinson, WI) through 19-, 8-, and 1.18-mm screens to yield long $(>19 \mathrm{~mm})$, medium $(<19 \mathrm{~mm},>8 \mathrm{~mm})$, short $(<8 \mathrm{~mm},>1.18 \mathrm{~mm})$, and fine $(<1.18 \mathrm{~mm})$ particles, as described previously (Lammers et al., 1996; Kononoff et al., 2003). Separated materials were then dried in a forced-air oven for $72 \mathrm{~h}$ at $55^{\circ} \mathrm{C}$. Comparison of TMR samples $(\mathrm{n}=$ 
Table 1. Ingredient and nutrient composition of the pre- and postpartum experimental diets

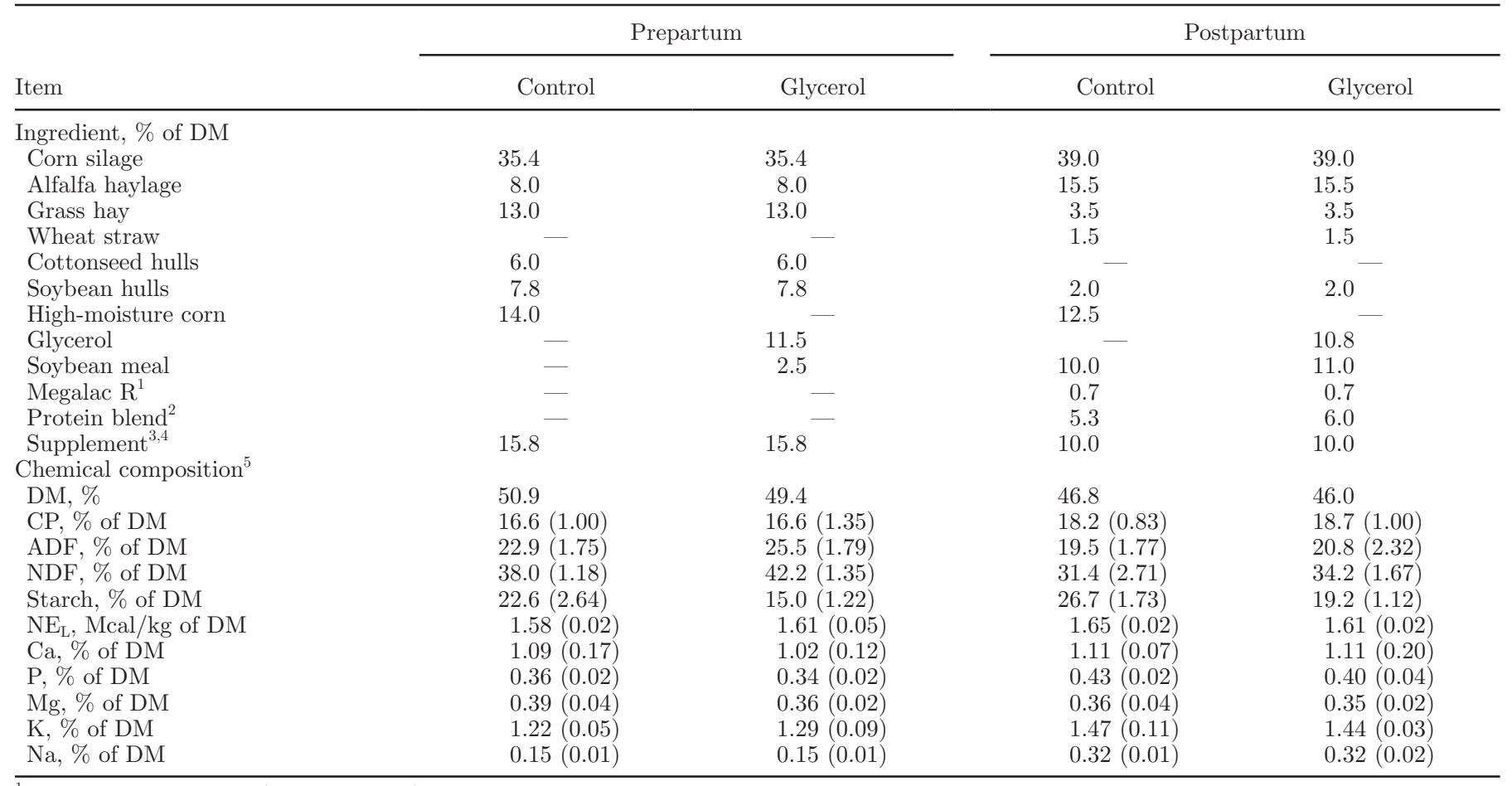

${ }^{1}$ Church \& Dwight Co. (Princeton, NJ).

${ }^{2}$ Contained 44\% Aminoplus (Ag Processing Inc., Omaha, NE), 3\% menhaden fish meal, and 53\% ProvAAL STD 5000 (Perdue AgriBusiness, Salisbury, MD).

${ }^{3}$ Prepartum: contained 38.29\% soybean meal, 25.65\% Bio-Chlor (Church \& Dwight Co.), 5.4\% $\mathrm{CaCO}_{3}, 2.16 \% \mathrm{CaHPO}_{4}, 1.08 \% \mathrm{MgO}, 1.08 \%$ $\mathrm{NaCl}, 1.65 \%$ mineral-vitamin premix $(16.11 \% \mathrm{Ca}, 2.11 \% \mathrm{~S}, 31,505 \mathrm{mg} / \mathrm{kg}$ of Zn, $8,036 \mathrm{mg} / \mathrm{kg}$ of Cu, 26,020 mg/kg of Mn, $140 \mathrm{mg} / \mathrm{kg}$ of Se, 473 $\mathrm{mg} / \mathrm{kg}$ of Co, $284 \mathrm{mg} / \mathrm{kg}$ of I, 1,440 $\mathrm{kIU} / \mathrm{kg}$ of vitamin A, $416 \mathrm{kIU} / \mathrm{kg}$ of vitamin D, 6,647 IU $/ \mathrm{kg}$ of vitamin E), 2.16\% MgSO, $5.08 \% \mathrm{Megalac} \mathrm{R}$ (Church \& Dwight Co.), $0.49 \%$ niacinamide (99.5\% niacin), 2.62\% yeast culture (Diamond V Mills, Cedar Rapids, IA), $1.8 \%$ vitamin E 20,000 (ADM Alliance Nutrition Inc., Quincy, IL), 0.08\% Rumensin 80 (Elanco Animal Health, Greenfield, IN), 2.62\% Omingen-AF (Prince-Agri Products, Quincy, IL), 1.08\% urea, 4.38\% blood meal, 3.81\% Aminoplus (Ag Processing Inc.), and 0.57\% menhaden fish meal.

${ }^{4}$ Postpartum: contained $25 \%$ dried molasses, $42.75 \%$ finely ground corn, $7.5 \% \mathrm{CaCO}_{3}, 5 \% \mathrm{CaHPO}_{4}, 6.2 \% \mathrm{NaHCO}_{3}, 2 \% \mathrm{MgO}, 2 \% \mathrm{DCAD} \mathrm{Plus}$ (Church \& Dwight Co.), $0.5 \%$ potassium magnesium sulfate, $2.5 \% \mathrm{NaCl}, 2.025 \%$ mineral-vitamin premix $(16.11 \% \mathrm{Ca}, 2.11 \% \mathrm{~S}, 31,505 \mathrm{mg} / \mathrm{kg}$ of $\mathrm{Zn}, 8,036 \mathrm{mg} / \mathrm{kg}$ of Cu, 26,020 mg/kg of Mn, $140 \mathrm{mg} / \mathrm{kg}$ of Se, $473 \mathrm{mg} / \mathrm{kg}$ of Co, $284 \mathrm{mg} / \mathrm{kg}$ of I, 1,440 kIU/kg of vitamin A, $416 \mathrm{kIU} / \mathrm{kg}$ of vitamin D, 6,647 IU $/ \mathrm{kg}$ of vitamin E), $0.25 \%$ niacinamide (99.5\% niacin), $2 \%$ yeast culture (Diamond V Mills), $0.213 \%$ vitamin E 20,000 (ADM Alliance Nutrition Inc.), 0.062\% Rumensin 80 (Elanco Animal Health), and 2\% Omingen-AF (Prince-Agri Products).

${ }^{5}$ Mean analysis for composite samples $(\mathrm{n}=5)$ and associated standard deviations (values in parentheses).

18) that were particle size separated as both fresh and frozen/thawed samples indicated ratios (mean and SD) of $1.03 \pm 0.11 \%, 1.00 \pm 0.04 \%, 0.97 \pm 0.03 \%$, and 1.05 $\pm 0.07 \%$ for long, medium, short, and fine particles between sample handling, indicating a lack of effect of freezing and thawing on the particle size distribution. Feed consumption at each time point was calculated by difference of the DM present at the beginning and end of each interval. Sorting behavior was evaluated by calculating the sorting index for particles retained on each sieve of the PSPS. The sorting index was calculated by expressing the actual DMI of each fraction as a percentage of the theoretical intake of the corresponding fraction (Leonardi and Armentano, 2003). Values $<100 \%$ equated to selective refusal and values $>100 \%$ equated to selective consumption. The glycerol content for each fraction of the TMR was determined by grinding the dried PSPS-separated samples through a 1-mm screen and mixing $2.5 \mathrm{~g}$ of each fraction in water to a total volume of $25 \mathrm{~mL}$. After $24 \mathrm{~h}$ of incubation at room temperature, the resulting suspension was centrifuged at $2,000 \times g$ for $15 \mathrm{~min}$ at $4^{\circ} \mathrm{C}$, and glycerol was determined in the supernatant by using a Free Glycerol Determination Kit FG0100-1KT (SigmaAldrich, St. Louis, MO).

\section{Data Analysis}

Data were analyzed using the MIXED procedure (SAS Institute, 1999). For the particle size of the initial diets, the model accounted for the effects of treatment (glycerol and control) and sieve size, and the interaction 
Table 2. Particle size distribution of the pre- and postpartum diets

\begin{tabular}{lccrr}
\hline Item & Control & Glycerol & SEM & $P$-value \\
\hline Prepartum, ${ }^{1} \%$ of DM retained on sieve & & & & \\
$>19 \mathrm{~mm}$ & 9.6 & 16.9 & 0.4 & $<0.05$ \\
$<19 \mathrm{~mm},>8 \mathrm{~mm}$ & 31.0 & 31.5 & 0.7 & 0.58 \\
$<8 \mathrm{~mm},>1.18 \mathrm{~mm}$ & 41.7 & 37.5 & 0.6 & $<0.05$ \\
$<1.18 \mathrm{~mm}$ (2) & 17.7 & 14.1 & 0.4 & $<0.05$ \\
Postpartum, ${ }^{2}$ DM retained on sieve & & & & \\
$>19 \mathrm{~mm}$ & 5.7 & 7.1 & 0.5 & 0.10 \\
$<19 \mathrm{~mm},>8 \mathrm{~mm}$ & 36.8 & 37.7 & 0.9 & 0.47 \\
$<8 \mathrm{~mm},>1.18 \mathrm{~mm}$ & 42.9 & 41.5 & 0.6 & 0.16 \\
$<1.18 \mathrm{~mm}$ & 14.6 & 13.7 & 0.7 & 0.36 \\
\hline
\end{tabular}

${ }^{1}$ Fed from 28 d prepartum through calving.

${ }^{2}$ Fed from calving through 56 DIM.

effect. For glycerol content within each particle size, the model accounted for only the effect of sieve size. The final model for intake and sorting accounted for the effects of treatment, DRTC, and time (relative to feeding), treatment $\times$ DRTC, treatment $\times$ time, DRTC $\times$ time, and treatment $\times$ DRTC $\times$ time. Data were analyzed separately for the prepartum and postpartum periods. Terms specified for the random statement were cow within treatment, DRTC $\times$ cow within treatment, time $\times$ cow within treatment, and DRTC $\times$ time $\times$ cow within treatment. Repeated measures analysis specified cow within treatment as the subject term and group equal to DRTC. A first-order autoregressive structure provided the model with the best fit according to Akaike's information criterion. All reported values are least squares means. To test whether sorting occurred, the sorting activity for each fraction of the PSPS was tested for a difference from 100 by using a $t$-test. Differences among means were tested using Tukey's multiple comparisons test. Significance was declared at $P \leq$ 0.05 , and trends were considered if $0.05 P \leq 0.15$

\section{RESULTS}

Because of the imprecision associated with target calving dates, the actual days relative to calving and associated standard deviations for feed intake measures were $-16 \pm 3.6,-9 \pm 3.7,+10 \pm 1.6,+17 \pm 2.4$, and $52 \pm 1.8$ DRTC. Adding glycerol to the prepartum diet increased $(P<0.05)$ the DM present as long particles $(>19 \mathrm{~mm})$ and reduced $(P<0.05)$ the proportion of DM retained as short $(<8-\mathrm{mm},>1.18-\mathrm{mm})$ and fine $(<1.18-\mathrm{mm})$ particles, but it did not change $(P>0.05)$ the proportion of DM present as medium $(<19-\mathrm{mm},>$ 8 -mm) particles. No effect of glycerol $(P>0.05)$ was observed on particle size distribution of the postpartum diets (Table 2). Average glycerol content of the prepartum and postpartum glycerol diets was $9.20 \pm 0.48 \%$ and $10.26 \pm 0.48 \%$, respectively. No difference $(P>$ 0.05 ) between the prepartum and postpartum diets was observed with regard to the glycerol distribution in each pan, although a tendency $(P=0.10)$ was observed for the postpartum diet to contain more glycerol associated with long particles (Table 3). Glycerol was not detected in the control diets.

No effect $(P=0.86)$ of diet on DMI was observed during the prepartum period, and daily DMI was 14.7 $\pm 0.4 \mathrm{~kg} / \mathrm{d}$ during this interval (Figure 1). A treatment $\times$ time effect relative to the feed delivery effect $(P<$ 0.01 ) was observed for DMI because of a reduction in DMI for cows fed glycerol during the first $4 \mathrm{~h}$ after feed delivery (7.22 vs. $5.59 \pm 0.35 \mathrm{~kg}$ for the control vs. glycerol diet, respectively) and on offsetting increase $(P$ $<0.01)$ in DM consumed from 12 through $24 \mathrm{~h}$ after

Table 3. Glycerol associated with particles in a TMR containing glycerol and fed during the pre- and postpartum periods

\begin{tabular}{lcccc}
\hline Glycerol, ${ }^{1} \%$ of DM & Prepartum & Postpartum & SEM & $P$-value \\
\hline$>19 \mathrm{~mm}$ & 8.5 & 11.2 & 1.0 & 0.06 \\
$<19 \mathrm{~mm},>8 \mathrm{~mm}$ & 10.1 & 11.6 & 1.0 & 0.30 \\
$<8 \mathrm{~mm},>1.18 \mathrm{~mm}$ & 9.5 & 9.6 & 1.0 & 0.57 \\
$<1.18 \mathrm{~mm}$ & 8.8 & 8.6 & 1.0 & 0.94 \\
\hline
\end{tabular}

${ }^{1}$ Glycerol associated with TMR particle size separated using the Penn State Particle Separator (Nasco, Fort Atkinson, WI).

${ }^{2}$ Main effects: prepartum vs. postpartum $\operatorname{diet}(P=0.14)$, tray $(P=0.22)$, and $\operatorname{diet} \times$ tray $(P=0.47)$.

${ }^{3} P$-value for prepartum vs. postpartum diet within the particle size. 


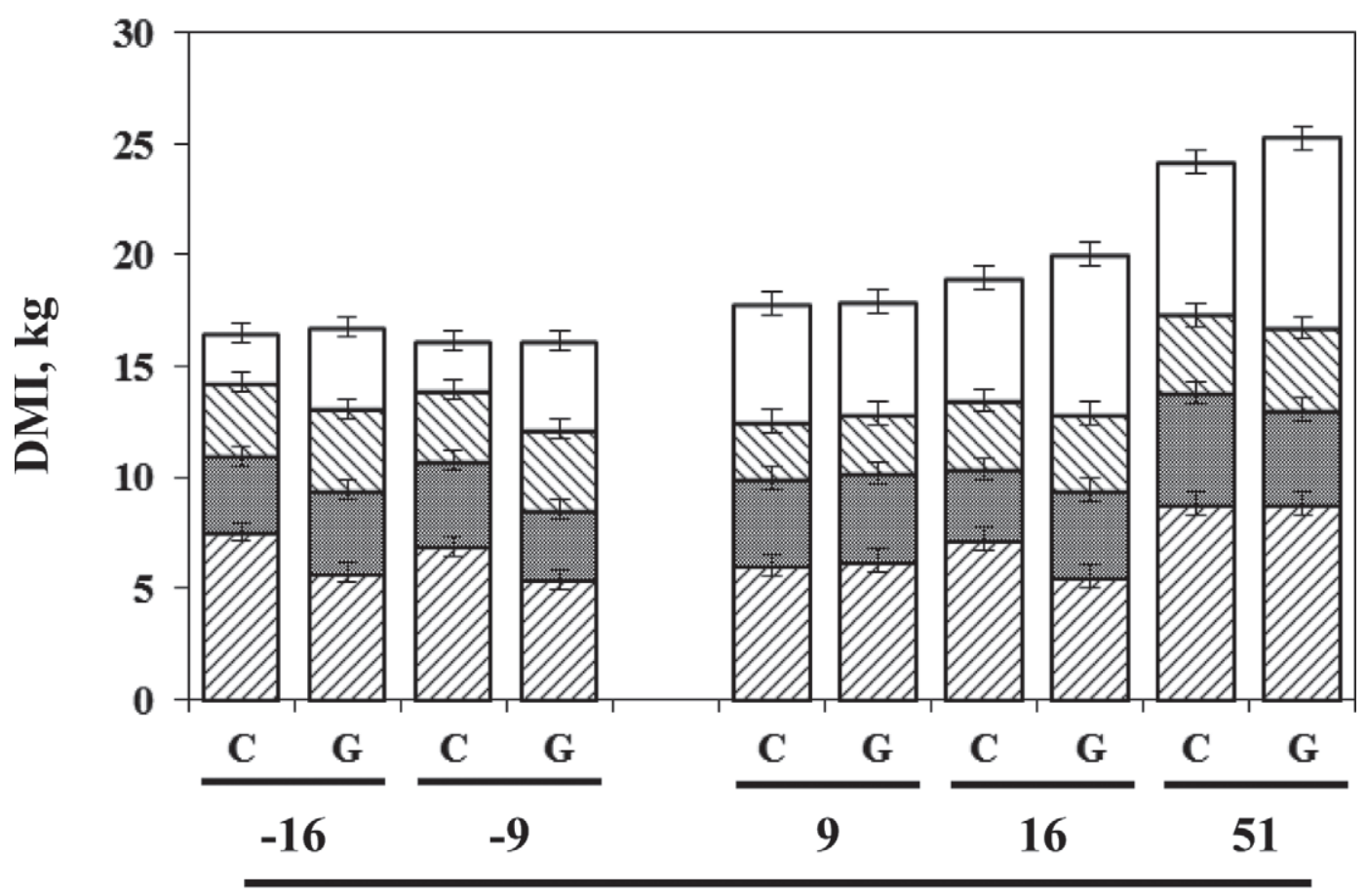

Days relative to calving

Figure 1. Effects of glycerol and day relative to calving on DMI pattern. Cows were fed the control diet (C) or a glycerol diet (G) from $28 \mathrm{~d}$ before calving through 56 DIM. On d $-16,-9,9,16$, and 51 relative to calving, the amount of feed offered was recorded. Feed remaining after 4 , 8,12 , and $24 \mathrm{~h}$ was determined. Dry matter intake was determined from the DM content of feed offered and feed refused. Data are least squares means and standard errors for kilograms of feed DM consumed from 0 and $4 \mathrm{~h}$ (right-leaning hatched boxes), 4 to $8 \mathrm{~h}$ (shaded boxes), 8 to $12 \mathrm{~h}$ (left-leaning hatched boxes), and 12 to $24 \mathrm{~h}$ (open boxes) after feed delivery for cows fed the C and G diets. Main effects prepartum: treatment, $P=0.86$; days relative to calving (DRTC), $P=0.41$; treatment $\times$ DRTC, $P=0.79$; time relative to feed delivery, $P<0.01$; treatment $\times$ time relative to feed delivery, $P<0.01$; DRTC $\times$ time relative to feed delivery, $P=0.59$; treatment $\times$ DRTC $\times$ time relative to feed delivery, $P=$ 0.51. Main effects postpartum: treatment, $P=0.46$; DRTC, $P<0.01$; treatment $\times$ DRTC, $P=0.73$; time relative to feed delivery, $P<0.01$; treatment $\times$ time relative to feed delivery, $P=0.15$; DRTC $\times$ time relative to feed delivery, $P<0.01$; treatment $\times$ DRTC $\times$ time relative to feed delivery, $P<0.05$.

feed delivery (2.22 vs. $3.82 \pm 0.35 \mathrm{~kg}$ for the control vs. glycerol diet, respectively). The DM of feed refused for the prepartum control and glycerol diets was $94 \pm$ $5.6 \%$ and $89 \pm 7.7 \%$ (mean and $\mathrm{SD}, \mathrm{n}=21$ ) of $\mathrm{DM}$ for feed offered.

Feed sorting data for the prepartum period (Table 4) indicated the lack of a main effect of glycerol on feed sorting in the absence of time $\times$ treatment effects. The effect of feed sorting was observed most frequently at 12 and $24 \mathrm{~h}$ after feed delivery, as determined by $t$-tests of particle distribution for each pan compared with the nonsorting value of $100 \%$, and feed sorting occurred both for cows fed diet glycerol and for those fed the control diet on $\mathrm{d}-16$ and -9 relative to calving. This pattern of sorting became more prevalent with time after feed delivery, contributing to a time $\times$ treatment effect $(P<0.05)$ for particles retained on the $19-$ and 1.18 -mm sieves (Figure 2).

No effect $(P>0.05)$ of glycerol on DMI was observed during the postpartum period, and daily DMI through
56 DIM was $20.2 \pm 0.5 \mathrm{~kg} / \mathrm{d}$. A treatment $\times$ DRTC $\times$ time effect was observed because of a greater quantity of TMR consumed during the interval from 12 through $24 \mathrm{~h}$ after feed delivery for cows fed the glycerol than for cows fed the control diet at the expense of feed consumed from 8 to $12 \mathrm{~h}$ after feeding, an effect that was greater at 16 and 51 DIM compared with 9 DIM (Figure 1). The DM of feed refused for the postpartum control and glycerol diets was $94 \pm 6.2 \%$ and $95 \pm 9.0 \%$ of DM for feed offered (means and SD, $\mathrm{n}=32$ ).

Cows sorted for long particles on d $9(113.2 \pm 7.78 \%)$ and $51(112.2 \pm 6.85 \%)$ of lactation, and against long particles at 16 DIM $(85.9 \pm 6.95 \%)$. Cows sorted for fine particles at 16 DIM $(102.2 \pm 6.81 \%)$ and against fine particles on d $9(70.5 \pm 6.81 \%)$ and $51(64.0 \pm$ $6.50 \%$ ) of lactation (Table 5). No treatment $\times$ DRTC effects $(P>0.05)$ were observed for particle-sorting behaviors. A treatment $\times$ time effect $(P<0.05)$ on feed sorting behavior was observed for medium, short, and fine particles, as well as a tendency $(P=0.07)$ for 
Table 4. Effect of glycerol on prepartum sorting (\%) of long, medium, short, and fine particles

\begin{tabular}{|c|c|c|c|c|c|c|c|c|c|c|c|c|c|c|}
\hline \multirow[b]{2}{*}{ Item } & \multirow[b]{2}{*}{ DRTC $^{1}$} & \multirow[b]{2}{*}{$\operatorname{Trt}^{2}$} & \multicolumn{4}{|c|}{ Time relative to feeding, ${ }^{3} \mathrm{~h}$} & \multirow[b]{2}{*}{$\mathrm{SEM}^{4}$} & \multicolumn{7}{|c|}{$P$-value } \\
\hline & & & 0 to 4 & 4 to 8 & 8 to 12 & 12 to 24 & & Trt & DRTC & $\begin{aligned} & \text { Trt } \\
\times & \text { DRTC }\end{aligned}$ & Time & $\begin{array}{c}\text { Trt } \\
\times \text { time }\end{array}$ & $\begin{array}{l}\text { DRTC } \\
\times \text { time }\end{array}$ & $\begin{array}{c}\text { Trt } \times \text { DRTC } \\
\times \text { time }\end{array}$ \\
\hline \multirow[t]{4}{*}{ 19-mm sieve } & -16 & $\mathrm{C}$ & 86.6 & 91.3 & $72.0^{*}$ & $65.0^{*}$ & \multirow[t]{4}{*}{7.65} & \multirow[t]{4}{*}{$<0.05$} & \multirow[t]{4}{*}{0.77} & \multirow[t]{4}{*}{0.74} & \multirow[t]{4}{*}{$<0.05$} & \multirow[t]{4}{*}{$<0.05$} & \multirow[t]{4}{*}{0.11} & \multirow[t]{4}{*}{0.64} \\
\hline & & G & 104.3 & 102.0 & 98.6 & 100.9 & & & & & & & & \\
\hline & -9 & $\mathrm{C}$ & 89.7 & $78.6^{*}$ & $75.6^{*}$ & $58.6^{*}$ & & & & & & & & \\
\hline & & G & 101.1 & 98.2 & $113.9^{*}$ & 93.2 & & & & & & & & \\
\hline \multirow[t]{4}{*}{ 8-mm sieve } & -16 & $\mathrm{C}$ & 105.9 & 107.8 & $112.1^{*}$ & $120.7^{*}$ & \multirow[t]{4}{*}{5.83} & \multirow[t]{4}{*}{0.76} & \multirow[t]{4}{*}{0.45} & \multirow[t]{4}{*}{0.10} & \multirow[t]{4}{*}{$<0.05$} & \multirow[t]{4}{*}{0.30} & \multirow[t]{4}{*}{0.89} & \multirow[t]{4}{*}{0.45} \\
\hline & & $\mathrm{G}$ & 107.2 & $111.6^{*}$ & $119.6^{*}$ & $138.0^{*}$ & & & & & & & & \\
\hline & -9 & $\mathrm{C}$ & $110.7^{*}$ & $114.3^{*}$ & $122.0^{*}$ & $134.8^{*}$ & & & & & & & & \\
\hline & & G & $109.4^{*}$ & $109.7^{*}$ & $111.7^{*}$ & $131.8^{*}$ & & & & & & & & \\
\hline \multirow[t]{4}{*}{ 1.18-mm sieve } & -16 & $\mathrm{C}$ & 102.2 & 101.4 & 104.2 & $106.9^{*}$ & \multirow[t]{4}{*}{3.32} & \multirow[t]{4}{*}{$<0.05$} & \multirow[t]{4}{*}{0.94} & \multirow[t]{4}{*}{0.18} & \multirow[t]{4}{*}{0.88} & \multirow[t]{4}{*}{$<0.05$} & \multirow[t]{4}{*}{0.71} & \multirow[t]{4}{*}{0.48} \\
\hline & & $\mathrm{G}$ & 97.2 & 95.0 & $93.2^{*}$ & $87.6^{*}$ & & & & & & & & \\
\hline & -9 & $\mathrm{C}$ & 100.1 & 101.6 & $101.7^{*}$ & 102.8 & & & & & & & & \\
\hline & & G & 97.0 & 96.7 & $93.5^{*}$ & $93.5^{*}$ & & & & & & & & \\
\hline Pan & -16 & $\mathrm{C}$ & 92.3 & 88.2 & $82.6^{*}$ & $65.0^{*}$ & 6.50 & 0.70 & 0.45 & 0.26 & $<0.05$ & 0.30 & 0.69 & 0.94 \\
\hline & & G & 87.8 & 88.6 & $76.7^{*}$ & $48.3^{*}$ & & & & & & & & \\
\hline & -9 & $\mathrm{C}$ & $87.7^{*}$ & $83.4^{*}$ & $71.7^{*}$ & $55.4^{*}$ & & & & & & & & \\
\hline & & G & 88.7 & 91.3 & $74.5^{*}$ & $52.7^{*}$ & & & & & & & & \\
\hline
\end{tabular}

${ }^{1} \mathrm{DRTC}=$ days relative to calving.

${ }^{2}$ Treatment (Trt): $\mathrm{C}=$ control; $\mathrm{G}=$ glycerol.

${ }^{3} \mathrm{An}$ asterisk $(*)$ indicates the value differs from 100 based on a $t$-test.

${ }^{4}$ Standard error of least squares means for treatment $\times$ day relative to calving $\times$ time relative to feed delivery $($ control, $\mathrm{n}=11 ;$ glycerol, $\mathrm{n}=12)$. 

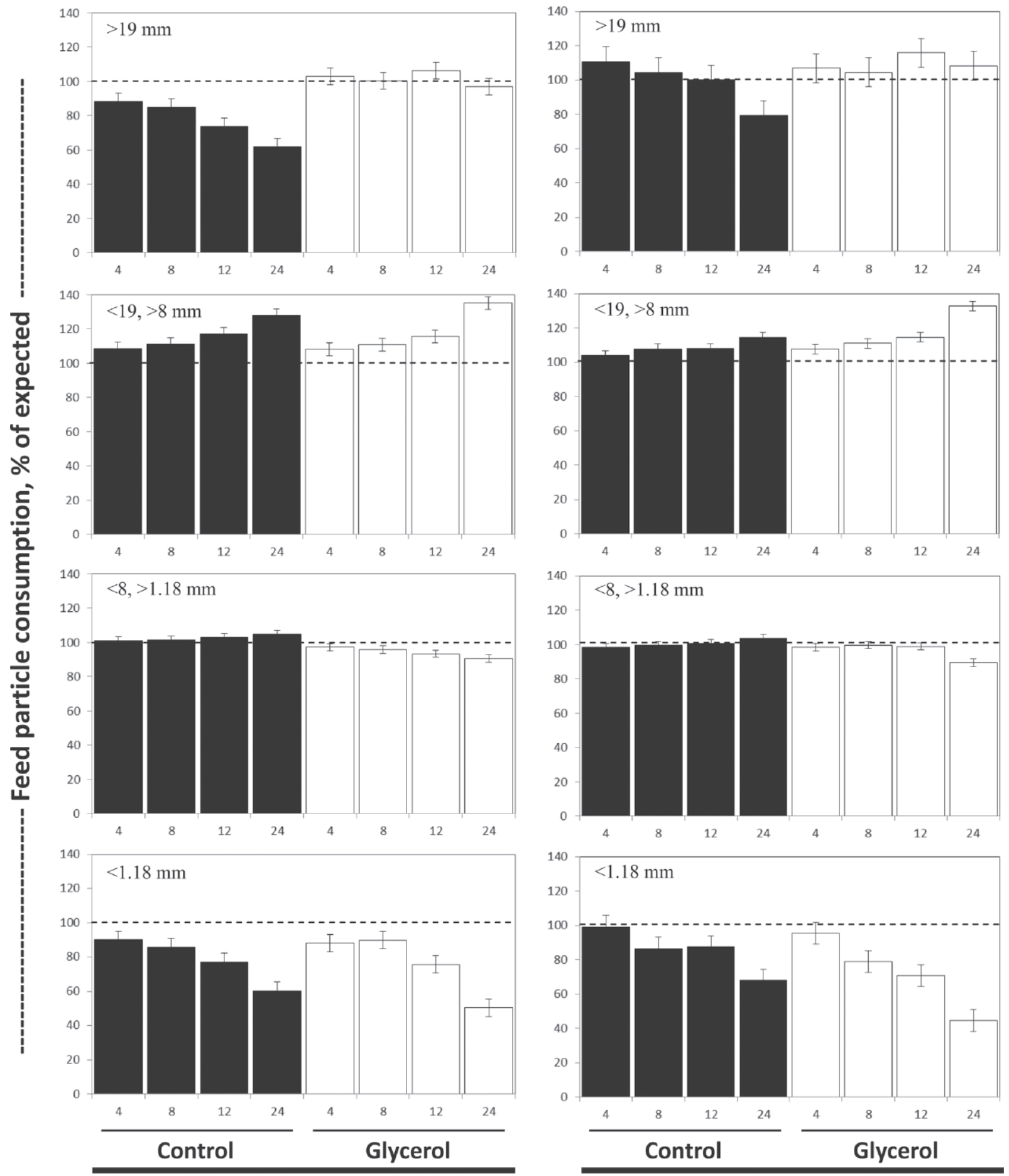

Prepartum

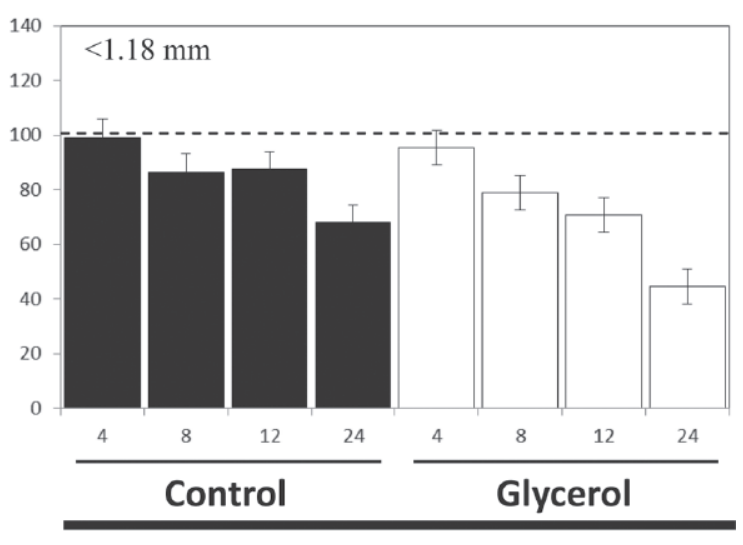

Postpartum

Figure 2. Effects of glycerol and time relative to feed delivery on feed-sorting behaviors. Cows were fed the control diet or a glycerol diet from 28 d before calving through 56 DIM. On d $-16,-9,9,16$, and 51 relative to calving, the feed particle profile of the TMR was determined using the Penn State Particle Separator (PSPS, Nasco, Fort Atkinson, WI) to yield long $(>19$-mm), medium $(<19$-mm, $>8$-mm), short $(<8$-mm, $>1.18-\mathrm{mm})$, and fine $(<1.18-\mathrm{mm})$ particles. At $4,8,12$, and $24 \mathrm{~h}$ after feed delivery, the feed remaining for each cow was weighed and mixed, and a 1.4-L subsample was obtained for particle size profiling. Feed particle consumption, as a percentage of expected, was determined from the DM retained on each screen of the PSPS in the TMR offered at feeding and the content on each screen at 4, 8, 12, and $24 \mathrm{~h}$ after feeding. Data were analyzed separately for prepartum and postpartum intervals. Prepartum: treatment $\times$ time effect $(P<0.05)$ for long $(>19$-mm) and short $(<8-\mathrm{mm},>1.18-\mathrm{mm})$ particles. Postpartum: treatment $\times$ time tendency $(P=0.07)$ for long $(>19-\mathrm{mm})$ particles, treatment $\times$ time effect $(P<$ $0.05)$ for medium $(<19-\mathrm{mm},>8-\mathrm{mm})$, short $(<8-\mathrm{mm},>1.18-\mathrm{mm})$, and fine $(<1.18-\mathrm{mm})$ particles. 
sorting in favor of long particles. When the data were averaged across DIM and considered relative to feed delivery, the cows fed the control diet tended to sort for long particles initially and then against long particles by $24 \mathrm{~h}$. Cows fed the control diet had mean sorting indices for long particles of 110.82, 104.28, 100.14, and $79.33 \pm 8.57 \%$ at $4,8,12$, and $24 \mathrm{~h}$ after feed delivery, and cows fed glycerol had mean sorting indices for long particles of $106.94,104.49,115.82$, and $108.21 \pm 8.39 \%$. Cows fed the control and glycerol diets sorted for $(P$ $<0.01)$ medium particles as time relative to feeding increased, and at $24 \mathrm{~h}$, sorting for medium particles was greater $(P<0.01)$ for cows fed glycerol. Cows fed glycerol sorted against short $(P<0.01)$ and fine $(P$ $=0.02$ ) particles as time relative to feeding increased, and means were different between the glycerol and control diets by $24 \mathrm{~h}$ after feed delivery $(P<0.01)$ only for short particles. No DRTC $\times$ time or treatment $\times$ DRTC $\times$ time effects $(P>0.05)$ of feed-sorting behaviors were observed.

\section{DISCUSSION}

The primary objective of the present study was to determine the effect of substituting glycerol for corn grain on the feed-sorting and eating patterns of transition dairy cows. The analysis of glycerol recovered in particles that were size separated using the PSPS indicated a uniform distribution of glycerol per unit of feed DM among these fractions. These data suggest that the adherent and conglomerate properties of glycerol are not specific to a class of particle sizes within the diets fed in this study as a TMR. The lack of differences in intake between the diets provides an opportunity to determine the effect of physical coating of particles with glycerol on sorting behavior.

In the present experiment, feed sorting was assessed by briefly removing feed from the bunk at each sampling time, mixing, removing a small subsample, and returning the mixed feed to the bunk, consequently disrupting any spatial sorting of TMR for each cow. Although the profile of TMR for all cows within a treatment was the same at feeding, the profile of particles remaining at subsequent times may have differed. The data presented here evaluated the profile of particles present at each sampling time relative to the initial profile of the TMR, disregarding the individual sorting patterns. Our primary goal was to assess the effect of adding glycerol to diets for transition cows. Pushing feed into the bunk throughout the day is a desirable practice on commercial dairies and that these push-ups are thought to stimulate the feed intake necessary to support greater milk production (Bach et al., 2008). Feed mixing is likely inherent to this activity, although the completeness of this mixing is unlikely to be complete. To avoid any bias in feed sampling, we mixed and subsampled the entire quantity of feed remaining at each time relative to feeding in a manner used previously for feed-sorting evaluation (Kononoff et al., 2003; Leonardi and Armentano, 2003; Hosseinkhani et al., 2008). More recent evidence indicates that this action may influence particle sorting in a manner that underestimates the extent of sorting for particles retained on a $29-\mathrm{mm}$ sieve, but this effect is evident only at $24 \mathrm{~h}$; for particles retained on an 18-mm sieve, this bias is observed at $16 \mathrm{~h}$ (Maulfair and Heinrichs, 2010). The approach used by Maulfair and Heinrichs (2010) may provide a more accurate representation of the sorting profiles for lactating cows, but we are not aware of a approach that has been used for transition cows. One of our primary observations is that the addition of glycerol virtually eliminates sorting against long particles. If a bias exists in sorting pattern because of experimental methods, as outlined by Maulfair and Heinrichs (2010), then sorting against long particles would be underestimated in our data, but only after $12 \mathrm{~h}$. The data presented here support the effect of glycerol in reducing sorting against long particles at least to $12 \mathrm{~h}$ and suggest that the effect persisted through $24 \mathrm{~h}$. Without independent corroboration of the effect of feed mixing on transition cow sorting behaviors, the value of these data for long particles at the 24-h sampling time is limited to the comparison of the effect of glycerol relative to the control diet because both treatments were manipulated in the same manner.

Glycerol decreased sorting against long particles of the prepartum diet but had no effect on sorting behaviors associated with long particles in the postpartum diet. The differential effect of glycerol in this regard may be due to a greater proportion of long-stemmed forage in the glycerol prepartum diet compared with the postpartum diet, thereby enhancing the opportunity for particle selection within the prepartum diet. Cows fed glycerol did not favor long particles in the prepartum period but instead displayed a lack of sorting behavior, whereas cows fed the control diet during the prepartum interval displayed sorting against long particles. This difference in particle sorting increased with time after feeding and was evident within $8 \mathrm{~h}$ after feed delivery. Likewise, cows fed glycerol sorted against short particles, a response that became evident as more time after feeding elapsed; however, cows fed the control diet displayed a general lack of sorting with regard to short particles. Therefore, the data from the prepartum interval do not support the hypothesis that glycerol results in sorting for long particles. Instead, the data support the conclusion that feeding glycerol in place of corn acts to reduce or eliminate sorting 
Table 5. Effect of glycerol on postpartum sorting (\%) of long, medium, short, and fine particles

\begin{tabular}{|c|c|c|c|c|c|c|c|c|c|c|c|c|c|c|}
\hline \multirow[b]{2}{*}{ Item } & \multirow[b]{2}{*}{ DRTC $^{1}$} & \multirow[b]{2}{*}{$\operatorname{Trt}^{2}$} & \multicolumn{4}{|c|}{ Time relative to feeding, ${ }^{3} \mathrm{~h}$} & \multirow[b]{2}{*}{$\mathrm{SEM}^{4}$} & \multicolumn{7}{|c|}{$P$-value } \\
\hline & & & 0 to 4 & 4 to 8 & 8 to 12 & 12 to 24 & & Trt & DRTC & $\begin{array}{l}\text { Trt } \times \\
\text { DRTC }\end{array}$ & Time & $\begin{array}{l}\text { Trt } \\
\times \text { time } \\
\end{array}$ & $\begin{array}{l}\text { DRTC } \\
\times \text { time }\end{array}$ & $\begin{array}{c}\text { Trt } \times \text { DRTC } \\
\times \text { time }\end{array}$ \\
\hline \multirow[t]{6}{*}{ 19-mm sieve } & 9 & C & 117.8 & 117.0 & 105.9 & 99.7 & \multirow[t]{6}{*}{15.75} & \multirow[t]{6}{*}{0.28} & \multirow[t]{6}{*}{$<0.05$} & \multirow[t]{6}{*}{0.79} & \multirow[t]{6}{*}{0.08} & \multirow[t]{6}{*}{0.07} & \multirow[t]{6}{*}{0.18} & \multirow[t]{6}{*}{0.56} \\
\hline & & G & 118.7 & 116.9 & 123.2 & 106.2 & & & & & & & & \\
\hline & 16 & $\mathrm{C}$ & 80.9 & 80.3 & $72.9^{*}$ & $73.7^{*}$ & & & & & & & & \\
\hline & & $\mathrm{G}$ & 91.3 & 91.1 & 92.4 & 104.2 & & & & & & & & \\
\hline & 51 & $\mathrm{C}$ & $133.6^{*}$ & 115.5 & 121.5 & $64.5^{*}$ & & & & & & & & \\
\hline & & G & 110.8 & 105.4 & 131.8 & 114.3 & & & & & & & & \\
\hline \multirow[t]{6}{*}{ 8-mm sieve } & 9 & $\mathrm{C}$ & 105.2 & 108.4 & 109.8 & 116.8 & \multirow[t]{6}{*}{4.60} & \multirow[t]{6}{*}{$<0.05$} & \multirow[t]{6}{*}{$<0.05$} & \multirow[t]{6}{*}{0.91} & \multirow[t]{6}{*}{$<0.05$} & \multirow[t]{6}{*}{$<0.05$} & \multirow[t]{6}{*}{0.32} & \multirow[t]{6}{*}{0.10} \\
\hline & & G & $111.6^{*}$ & $113.4^{*}$ & $119.9^{*}$ & $130.5^{*}$ & & & & & & & & \\
\hline & 16 & $\mathrm{C}$ & 98.4 & 100.1 & 100.5 & $108.7^{*}$ & & & & & & & & \\
\hline & & G & 103.5 & $107.8^{*}$ & $107.9^{*}$ & $122.4^{*}$ & & & & & & & & \\
\hline & 51 & $\mathrm{C}$ & 107.9 & $115.0^{*}$ & $113.4^{*}$ & $118.4^{*}$ & & & & & & & & \\
\hline & & G & 107.5 & 111.9 & $115.9^{*}$ & $145.3^{*}$ & & & & & & & & \\
\hline \multirow[t]{6}{*}{ 1.18-mm sieve } & 9 & $\mathrm{C}$ & 98.9 & 98.1 & 100.0 & 101.7 & \multirow[t]{6}{*}{3.88} & \multirow[t]{6}{*}{0.05} & \multirow[t]{6}{*}{$<0.05$} & \multirow[t]{6}{*}{0.79} & 0.27 & $<0.05$ & 0.69 & 0.32 \\
\hline & & G & $94.3^{*}$ & 97.0 & 95.2 & $92.8^{*}$ & & & & & & & & \\
\hline & 16 & $\mathrm{C}$ & 101.0 & 104.1 & 104.9 & $106.5^{*}$ & & & & & & & & \\
\hline & & $\mathrm{G}$ & 103.1 & 103.2 & 105.3 & 93.8 & & & & & & & & \\
\hline & 51 & $\mathrm{C}$ & 95.2 & 96.3 & 97.1 & 102.8 & & & & & & & & \\
\hline & & $\mathrm{G}$ & 97.8 & 98.8 & 96.3 & $81.9^{*}$ & & & & & & & & \\
\hline Pan & 9 & $\mathrm{C}$ & 86.6 & $80.2^{*}$ & $76.5^{*}$ & $59.2^{*}$ & 11.03 & 0.12 & $<0.01$ & 0.94 & $<0.01$ & $<0.05$ & 0.38 & 0.18 \\
\hline & & G & 83.9 & $71.9^{*}$ & $60.5^{*}$ & $45.3^{*}$ & & & & & & & & \\
\hline & 16 & $\mathrm{C}$ & $127.6^{*}$ & 110.7 & 117.4 & 86.0 & & & & & & & & \\
\hline & & G & 113.0 & 94.6 & 95.9 & 67.3 & & & & & & & & \\
\hline & 51 & $\mathrm{C}$ & 83.6 & $83.6^{*}$ & $68.8^{*}$ & $69.0^{*}$ & & & & & & & & \\
\hline & & $\mathrm{G}$ & 84.8 & $70.0^{*}$ & $55.5^{*}$ & $51.3^{*}$ & & & & & & & & \\
\hline
\end{tabular}

DRTC $=$ days relative to calving.

${ }^{2}$ Treatment (Trt): $\mathrm{C}=$ control; $\mathrm{G}=$ glycerol.

${ }^{3} \mathrm{An}$ asterisk $(*)$ indicates the value differs from 100 based on $t$-test.

${ }^{4}$ Standard error of least squares means for treatment $\times$ day relative to calving $\times$ time relative to feed delivery $($ control, $\mathrm{n}=11 ; \mathrm{glycerol}, \mathrm{n}=12)$. 
against long particles by close-up dry cows. Previous data indicated that close-up dry cows sort against long particles (Hosseinkhani et al., 2008), and the degree of selection against long particles appears to be more pronounced than for midlactation cows fed a high-grain diet (DeVries et al., 2007). The level of sorting against long particles for cows fed the control diet in the present study appears even more pronounced during the last 12 $\mathrm{h}$ after feeding than the pattern of sorting by transition cows receiving fresh feed twice daily (Hosseinkhani et al., 2008). It would appear that feeding glycerol may be particularly beneficial in transition cows that are fed once daily. The effect of glycerol in reducing or eliminating sorting against long particles and distributing intake more evenly through the day may reduce the potential diurnal variation in the rumen environment.

The first reported effect of liquid addition on the sorting behaviors of lactating cows (DeVries and Gill, 2012) was published while the present work was in review and indicated a similar effect of the addition of a liquid feed composed of cane molasses, corn steep liquor, and corn distillers grains to reduce sorting against long particles. The present work extends those observations to include effects of glycerol in reducing feed sorting and altering the feed intake pattern when used as a replacement for corn in diets for transition cows.

Social structure may influence feeding behavior, especially when access to feed resources is reduced (DeVries et al., 2005). Consequently, the nutrition of subordinate cows may be compromised by the limited frequency and duration of access to the feed bunk (DeVries et al., 2005). Sorting for short particles by more competitive cows in a group places subordinate cows at risk for consuming a diet with reduced energy density relative to demands (Hosseinkhani et al., 2008). Furthermore, within-day sorting may negatively influence nutritional status for transition cows that face competition for feed bunk access because dominant cows tend to select against long particles (Hosseinkhani et al., 2008). Consequently, a lack of discrimination against long particles when glycerol is included in the diet may reduce the effects of social structure and competiveness in close-up cow rations. However, because feed sorting by individually housed cows (Leonardi and Armentano, 2007) and competitively housed cows (DeVries et al., 2004) differs, the effects of glycerol on the lack of sorting against long particles must be further evaluated to determine the effect of glycerol on variation in nutrient consumption in close-up dry cows housed in groups and given access to a common feed bunk.

Glycerol fed during the postpartum period increased sorting for medium particles. Control cows sorted for short particles, but cows fed glycerol did not display a similar behavior. Comparisons between treatments represent a difference in sorting of less than $10 \%$, but of a magnitude similar to changes in sorting behaviors observed when other sweet-tasting ingredients were added to the TMR of early postpartum cows (Penner and Oba, 2009). Feed sorting in favor of smaller particles is thought to be associated with reduced rumen $\mathrm{pH}$ because of a reduction in effective NDF intake (DeVries et al., 2008; Hosseinkhani et al., 2008). A reduction in sorting for smaller particles may be partly due to differences in the profile of particles between the diets because the glycerol diets contained fewer medium and small particles as a result of substitution of glycerol for corn grain, and therefore reduce the opportunity to sort for these particles. The addition of glycerol and sorting for medium particles may reduce the potential for variations in the rumen environment in transition cows, provided the medium-sized particles consumed are associated with increased physically effective fiber intake.

The hypothesis of feeding behavior tested in the present experiment using an assessment of power for mixed model analysis (Stroup, 1999) and the model variance for cow within treatment, and the assumption that a difference in feed-sorting behaviors of $10 \%$ was biologically relevant yielded a power of the tests for treatments of $0.99,0.99,0.99$, and 0.86 for long, medium, short, and fine particles. Caution should be exercised in extrapolating these data to cow behaviors during the transition period, given the high within-cow variability associated with feeding activities and the fact that samples were collected over a limited number of days (Dado and Allen, 1994).

\section{CONCLUSIONS}

Replacing corn grain with glycerol did not affect overall DMI but increased the proportion of DMI consumed at later periods of the day. The addition of glycerol in late gestation decreased feed intake during the first $4 \mathrm{~h}$ after feeding by $23 \%$ but increased feed consumed during the last $12 \mathrm{~h}$ by $72 \%$. Replacing corn with glycerol reduced sorting against long feed particles by close-up dry cows. Feeding glycerol increased sorting for medium particles, and the presence of glycerol reduced cow sorting for short particles. The data support a feed intake and particle size consumption that reduces sorting against long particles and therefore may prove beneficial for the health of transition cows.

\section{ACKNOWLEDGMENTS}

The authors acknowledge the support of Perry Doane and Archer Daniels Midland (Decatur, IL) for the generous gift of glycerol for this project, the 
help afforded them by Michael Grott and the Purdue Dairy Research and Education Center staff, and the laboratory expertise of Stephanie Koser (Department of Animal Sciences, Purdue University, West Lafayette, IN). This project was supported by the Agricultural Food Research Initiative of the National Institute of Food and Agriculture, US Department of Agriculture (Washington, DC; Grant No. 2007-55618-18237). Scholarship support for E. R. Carvalho was from Coordenação de Aperfeiçoamento de Pessoal de Nível Superior (CAPES), Ministério da Educação (Brasília, Brazil).

\section{REFERENCES}

AOAC International. 2000. Official Methods of Analysis. 17th ed. AOAC Int., Gaithersburg, MD.

Bach, A., N. Valls, A. Solans, and T. Torrent. 2008. Associations between nondietary factors and dairy herd performance. J. Dairy Sci. 91:3259-3267.

Bell, F. R., and R. L. Kitchell. 1966. Taste reception in the goat, sheep and calf. J. Physiol. 183:145-151.

Carvalho, E. R., N. S. Schmelz, H. M. White, and S. S. Donkin. 2011. Replacing corn with glycerol in diets for transition dairy cows. J. Dairy Sci. 94:908-916.

Dado, R. G., and M. S. Allen. 1994. Variation in and relationships among feeding, chewing, and drinking variables for lactating dairy cows. J. Dairy Sci. 77:132-144.

DeVries, T. J., K. A. Beauchemin, and M. A. G. von Keyserlingk. 2007. Dietary forage concentration affects the feed sorting behavior of lactating dairy cows. J. Dairy Sci. 90:5572-5579.

DeVries, T. J., F. Dohme, and K. A. Beauchemin. 2008. Repeated ruminal acidosis challenges in lactating dairy cows at high and low risk for developing acidosis: Feed sorting. J. Dairy Sci. 91:39583967.

DeVries, T. J., and R. M. Gill. 2012. Adding liquid feed to a total mixed ration reduces feed sorting behavior and improves productivity of lactating dairy cows. J. Dairy Sci. 95:2648-2655.

DeVries, T. J., M. A. G. von Keyserlingk, and K. A. Beauchemin. 2005. Frequency of feed delivery affects the behavior of lactating dairy cows. J. Dairy Sci. 88:3553-3562.

DeVries, T. J., M. A. G. von Keyserlingk, and D. M. Weary. 2004. Effect of feeding space on the inter-cow distance, aggression, and feeding behavior of free-stall housed lactating dairy cows. J. Dairy Sci. 87:1432-1438.

Donkin, S. S., S. L. Koser, H. M. White, P. H. Doane, and M. J. Cecava. 2009. Feeding value of glycerol as a replacement for corn grain in rations fed to lactating dairy cows. J. Dairy Sci. 92:5111-5119.

Drackley, J. K. 1999. Biology of dairy cows during the transition period: The final frontier? J. Dairy Sci. 82:2259-2273.

Farahnaky, A., S. Ansaria, and M. Majzoobi. 2009. Effect of glycerol on the moisture sorption isotherms of figs. J. Food Eng. 93:468-473.

Goering, H. K., and P. J. Van Soest. 1970. Forage Fiber Analysis (Apparatus, Reagents, Procedures and Some Applications). Agric. Handbook No. 379. US Dept. Agric., Agric. Res. Serv., Washington, DC.
Grummer, R. R. 1995. Impact of changes in organic nutrient metabolism on feeding the transition dairy cow. J. Anim. Sci. 73:28202833.

Hosseinkhani, A., T. J. DeVries, K. L. Proudfoot, R. Valizadeh, D. M. Veira, and M. A. G. von Keyserlingk. 2008. The effects of feed bunk competition on the feed sorting behavior of close-up dry cows. J. Dairy Sci. 91:1115-1121.

Kononoff, P. J., A. J. Heinrichs, and D. R. Buckmaster. 2003. Modification of the Penn State Forage and Total Mixed Ration Particle Separator and the effects of moisture content on its measurements. J. Dairy Sci. 86:1858-1863.

Krause, K. M., and G. Oetzel. 2006. Understanding and preventing subacute ruminal acidosis in dairy herds: A review. Anim. Feed Sci. Technol. 126:215-236.

Lammers, B. P., D. R. Buckmaster, and A. J. Heinrichs. 1996. A simple method for the analysis of particle sizes of forage and total mixed rations. J. Dairy Sci. 79:922-928.

Lee, C. K. 1987. The chemistry and biochemistry of the sweetness of sugars. Adv. Carbohydr. Chem. Biochem. 45:199-351.

Leonardi, C., and L. E. Armentano. 2003. Effect of quantity, quality, and length of alfalfa hay on selective consumption by dairy cows. J. Dairy Sci. 86:557-564.

Leonardi, C., and L. E. Armentano. 2007. Feed selection by dairy cows fed individually in a tie-stall or as a group in a free-stall barn. J. Dairy Sci. 90:2386-2389.

Lesmeister, K. E., and A. J. Heinrichs. 2005. Effects of adding extra molasses to a texturized calf starter on rumen development, growth characteristics, and blood parameters in neonatal dairy calves. J. Dairy Sci. 88:411-418.

Maulfair, D. D., and A. J. Heinrichs. 2010. Technical note: Evaluation of procedures for analyzing ration sorting and rumen digesta particle size in dairy cows. J. Dairy Sci. 93:3784-3788.

Nombekela, S. W., M. R. Murphy, H. W. Gonyou, and J. I. Marden. 1994. Dietary preferences in early lactation cows as affected by primary tastes and some common feed flavors. J. Dairy Sci. 77:2393-2399

NRC. 2001. Nutrient Requirements of Dairy Cattle. 7th rev. ed. Natl. Acad. Sci., Washington, DC.

Oelker, E. R., C. Reveneau, and J. L. Firkins. 2009. Interaction of molasses and monensin in alfalfa hay- or corn silage-based diets on rumen fermentation, total tract digestibility, and milk production by Holstein cows. J. Dairy Sci. 92:270-285.

Penner, G. B., and M. Oba. 2009. Increasing dietary sugar concentration may improve dry matter intake, ruminal fermentation, and productivity of dairy cows in the postpartum phase of the transition period. J. Dairy Sci. 92:3341-3353.

Roper, S. D. 2007. Signal transduction and information processing in mammalian taste buds. Pflugers Arch. 454:759-776.

SAS Institute. 1999. SAS/STAT User's Guide: Statistics. Version 9.2 ed. SAS Inst. Inc., Cary, NC.

Stone, W. C. 2004. Nutritional approaches to minimize subacute ruminal acidosis and laminitis in dairy cattle. J. Dairy Sci. 87(ESuppl.):E13-E26.

Stricklin, W. R., and C. C. Kautz-Scanavy. 1983. The role of behavior in cattle production: A review of research. Appl. Anim. Ethol. 11:359-390.

Stroup, W. W. 1999. Mixed model procedures to assess power, precision, and sample size in the design of experiments. Pages 15-24 in Proc. Biopharm. Sect. Mtg. Am. Stat. Assoc. Am. Stat. Assoc., Baltimore, MD. 